\title{
Creative Commons Licenses: Empowering Open Access ${ }^{1}$
}

Thomas Margoni, Lecturer in Law, University of Stirling, UK

Diane M. Peters, General Counsel, Creative Commons

\section{Introduction: Open Access}

Open access (OA) is a concept that in recent years has acquired popularity and widespread recognition. ${ }^{2}$ International statements and scholarly analysis converge on the following main characteristics of open access: free availability on the public Internet, permission for any users to read, download, copy, distribute, print, search, and link to the full texts of these articles, crawl them for indexing, pass them as data to software, and use them for any other lawful purpose, without financial, legal, or technical barriers other than those inseparable from gaining access to the Internet itself. The only legal constraint on reproduction and distribution, and the only role for copyright in this domain, should be to give authors control over the integrity of their work and the right to be properly acknowledged and cited. ${ }^{3}$

More formally, OA has been defined as works that are digital, online, free of charge, and free of most copyright and licensing restrictions. ${ }^{4}$ Crucially, OA gives readers the right to republish or reuse content as they like, so long as the author and publisher receive proper attribution. This is fundamental, since terminology closely associated with $\mathrm{OA}$ has been misused to describe publication models that share nothing with the motives underpinning the OA movement. ${ }^{5}$ This confusion can be largely attributed to the blossoming of publishing business models based on the offer of an "open access" option that charges for Internet publication without granting readers full reuse rights as described. These publishers have adopted a business model through which authors pay for immediate publication on the Internet but the publisher nonetheless retains exclusive commercial or other types of reuse rights for itself. ${ }^{6}$ Agreements like the latter do not comply with the aforementioned definitions of OA and therefore ought not be characterized as open access.

\footnotetext{
1 (C) 2016 Creative Commons and Thomas Margoni. This paper is licensed under a Creative Commons Attribution 4.0 license.

2 See Willinsky J. (2005), The Access Principle - The Case for Open Access to Research and Scholarship, MIT Press; Suber P. (2012), Open Access, MIT Press.

See Berlin Declaration on Open Access to Knowledge in the Sciences and Humanities of 2003, available at http://openaccess.mpg.de/BerlinDeclaration (last accessed January 2016); Bethesda Statement on Open Access Publishing of 2003, available at http://legacy.earlham.edu/ peters/fos/bethesda.htm (last accessed January 2016) Budapest Open Access Initiative of 2002, available at http://www.budapestopenaccessinitiative.org/read (last accessed January 2016).

4 See Suber P., Open Access, MIT Press, 2012.

5 See Carroll M. (2011), Why Full Open Access Matters, PLOS Biology, PLoS Biol 9(11).

6 Id.
} 
Other expressions such as hybrid open access, ${ }^{7}$ or the less neutral "predatory" open access ${ }^{8}$ have been coined to describe a variety of other business models, such as non open access journals that offer the possibility of "buying back" the right to publish as OA. For the sake of terminological clarity and consistency, a publication can be defined as true OA only if it meets the requirements identified consistent with the relevant international declarations and supported by the dominant literature in the field. While hybrid OA models may meet the technical requirements of OA, they quite often do not comply with the principles of OA. In particular, the way in which the costs to "buy back" the right to publish in OA (known as an Article Processing Charge, or APC) is calculated has been criticisms by authors, OA publishers and funding agencies. ${ }^{9}$ Some recent literature $^{10}$ has offered evidence that hybrid OA does not generate the same benefits in terms of widespread distribution that OA journals do, supporting the conclusion that the socio-economic dynamics behind this type of business model do not adhere to OA principles.

\section{Copyright and the Publishing Industry}

Authors automatically receive copyright protection the moment they create (and in most jurisdictions also fix in a tangible form) their work. The enjoyment and exercise of copyright is not subject to formalities such as registration in any of the 169 countries around the world that to date have joined the Berne Convention for the Protection of Literary and Artistic Works, ${ }^{11}$ although many countries have retained until relatively recently formalities (for example, until 1989 the United States required a publication be accompanied by a copyright notice (C)).

Subscription-based journals typically require authors to transfer all or some of their exclusive rights under copyright to the journal as a term of the publication agreement. Those publishers then restrict access to paying customers, and use the threat of copyright infringement to deter competing publications from republishing or reusing the journal's content without a license. ${ }^{12}$ Some journals allow the author to retain all or some of her copyright, but require the grant of a non-exclusive

\footnotetext{
7 See Björk B., The Hybrid Model for Open Access Publication of Scholarly Articles - a Failed Experiment?, J. Am. Soc. Inf. Sci., 63: 14961504.

8 See Beall J., Predatory publishers are corrupting open access, Nature, 489, 179 (13 September 2012),

9 See Björk B., The Hybrid Model for Open Access Publication of Scholarly Articles - a Failed Experiment?, J. Am. Soc. Inf. Sci., 63: 1496-,1504; Nature's press release on the website access price reduction due to the increase in OA publishing http://www.nature.com/press releases/emboopen.html; Wellcome Trust report on the cost of OA publishing calling for more transparency "The cost of open access publishing: a progress report" available at http://blog.wellcome.ac.uk/2014/03/28/the-cost-of-open-access-publishing-a-progress-report (all last accessed January 2016).

10 See Mueller-Langer F., Watt R., The Hybrid Open Access Citation Advantage: How Many More Cites is a \$3,000 Fee Buying You?, Max Planck Institute for Innovation \& Competition Research Paper No. 14-02, available at: http://ssrn.com/abstract=2391692.

11 See Berne Convention for the Protection of Literary and Artistic Works of 1886 as amended on September 28, 1979.

12 See Carroll M (2011), Why Full Open Access Matters, PLOS Biology, PLoS Biol 9(11)
} 
license. Where no publication agreement is signed or permission otherwise granted, the author retains copyright. ${ }^{13}$

OA publishing uses this permission model to grant readers broad reuse rights to encourage the widespread republication and reuse of articles. Open access publishers do not need to police the behavior of readers or rival publishers except to the extent journal content is reused without giving the author or the journal proper credit. The standard means for granting readers permission is through a Creative Commons Attribution license (CC BY).

\section{Creative Commons Legal Tools Enable Open Access}

The dominant legal tools used to achieve the ambitious objectives of open access publishing are licenses and other legal tools stewarded and published by Creative Commons. Creative Commons (CC) is a non-profit international organization that supports a flexible view of copyright in contrast to the traditional "all rights reserved" framework. CC offers licenses and other tools for free to the public. ${ }^{14}$ The most popular for purposes of OA publishing are the CC public licenses, which allow authors to retain copyright while granting certain, specific permission to reuse and remix works provided specified conditions are met. CC also offers the CC0 Public Domain Dedication, which effectively relinquishes all copyright in a work worldwide. CC0 (read "CC zero") is particularly popular in the fields of research and data.

\section{1) Creative Commons Licenses}

All Creative Commons licenses offer a core set of reuse rights to the public. Each of the six CC licenses requires attribution and protects the integrity of the original creator. ${ }^{15}$ These rights include the right to reproduce (make copies), redistribute, communicate to the public, make available to the public and perform the work in its original form, at least for non commercial purposes, subject to the condition that proper attribution is provided (known as the BY element). Licensors can add from among three additional license conditions and restrictions:

- $\mathrm{NC}-$ Non Commercial. The licensor grants the permissions specified above but only if the work is used in a manner that is not primarily intended for, or directed towards, commercial

13 Id.

14 See www.creativecommons.org (last accessed January 2016)

15 See http://creativecommons.org/choose (last accessed January 2016). 
advantage or (private) monetary compensation. ${ }^{16}$ This license condition is not compatible with the OA definition.

- ND - NoDerivatives. The licensor grants the permissions specified above, specifically reserving the right to create and distribute derivative works. Because this license term prevents creation of derivative works, including translations into other languages, use of a $\mathrm{CC}$ license with this element is inconsistent with most understandings of OA.

- SA - ShareAlike. The licensor permits the creation of derivative works, but only if the user licenses her contributions to the derivative work under the same terms.

All CC licenses contain terms that protect the integrity of the original author and her work.

- The "non-endorsement" clause in all CC licenses prohibits uses that suggest or imply that the licensor of the work in any way sponsors, supports or approves of the uses or adaptations of the work.

- For works made available under a CC license that does not contain the NoDerivatives restriction, the user must take reasonable steps to clearly label, demarcate or otherwise identify any changes she makes to the original work. This alerts reusers of the altered work that the original has been modified.

- All adaptations and collections of works offered under Creative Commons licenses must state that they are not the original, and must contain a link back to the original as published. This alerts subsequent reusers as mentioned above, and enables them to view the original in its unaltered form.

- A licensor may request that credit be removed from any specific adaptations or collections while retaining her right to require attribution elsewhere.

Worth noting in the OA context particularly is that Creative Commons expanded the license grant in the newest version of its licenses, version 4.0. The 4.0 version of the licenses not only grants the stated permission and conditions as a matter of copyright and neighboring rights, but also to use the work in ways that would otherwise be prevented by rights that are closely related, including the European database sui generis right. This is an important feature in the context of Open Access, because it ensures that activities such as text and data mining of OA papers and accompanying data are allowed. ${ }^{17}$ This was not necessarily the case under earlier versions of the

\footnotetext{
${ }^{16}$ The requirement of the compensation be private has been removed from version 4; however, Creative Commons made clear at the time of publication that the elimination of that term did not change the meaning or scope of the restriction. See Draft 3 publication notes here: https://wiki.creativecommons.org/wiki/4.0/NonCommercial. 
license.

\section{2) CC0 Public Domain Dedication}

Another $\mathrm{CC}$ tool that deserves attention in the open access context is $\mathrm{CC} 0 . \mathrm{CC} 0$ works to relinquish and forever waive all copyright and related rights in a work on a worldwide basis. The scope of the $\mathrm{CC} 0$ waiver is much broader than that contained in the $\mathrm{CC}$ licenses, including not only copyright, neighboring rights and sui generis database rights, but also publicity and privacy rights, and rights protecting against unfair competition, all to the extent those rights are held or controlled by the person applying $\mathrm{CC} 0$ (the "affirmer"). With $\mathrm{CC} 0$, the affirmer waives, abandons, and surrenders (or licenses to the same effect in any event the waiver is deemed ineffective) all of her copyright and related rights and associated claims and causes of action on the work. $\mathrm{CC} 0$ is particularly popular and dominant in the field of open data.

CC0 can be beneficial for publishers of open access works because of the broad permissions it grants for others to build upon the scholarship and research. Most especially, CC0 is impactful for sharing underlying data, which much of the time is subject to only thin copyright at best. CC0 promotes maximum reuse, subject to scholarly norms and practices including citing those who aggregated or compiled the data and research and indicating changes.

\section{Why Open Access Matters}

Getting OA licensing right through the use of standardized and well-understood licensing is central to increasing the advancement and impact of research and scholarship. Publishing consistent with best $\mathrm{OA}$ practices increases the audience for scientific research and overcomes the increasingly high price barrier to access imposed by the traditional, subscription-based publishing model. ${ }^{18}$

The granting of liberal reuse rights through the use of the standard licenses published by Creative Commons permits users to republish, quote, and overcome language barriers through translation. To accomplish these important objectives, the OA model makes two structural changes to the traditional, subscription-based model. ${ }^{19}$ The first is to shift the financing for publication from readers, through subscription fees, to authors (often through their funders), through article processing fees, although there are growing instances of OA publishing not associated with an

18 See Carroll M (2011), Why Full Open Access Matters, PLOS Biology, PLoS Biol 9(11). 
author pays model. ${ }^{20}$ The second is to shift from a model that uses copyright to control reuse of content, to one that uses copyright to encourage republication, preservation, and translation.

Open access goals do not subvert or undermine the role of publishers as the driving force in an oligopolistic. ${ }^{21}$ The open and competitive market that OA engenders ought be viewed favorably not only by economists but also by the community of scholars and society at large. This model is synonymous with faster innovation and better conditions for consumers - a larger consumer surplus, as economists characterize it. ${ }^{22}$ Open access also decentralizes and democratizes the way in which scholarship is published and empowers and enables means for access by removing barriers. ${ }^{23}$ Open access is not just an innovative means of publishing academic papers; OA is also a tool that can make science - and society more generally - more open, dynamic, accountable and participatory, and Creative Commons licenses are central to that success.

Traditionally, two "roads" to open access publishing have been identified: the Golden Road and the Green Road. The Golden Road refers to publications in $\mathrm{OA}$ journals while the Green Road refers to archiving in institutional repositories under OA licenses. Article processing fees are usually associated with the Golden option, however, a growing number of journals (especially those whose publishers are not commercial, but institutional publishers) do not charge fees. In this regard, it is important to conceptually differentiate the technical-legal aspect of (Golden) OA publishing and the (usually, but not necessarily) associated business model where "author pays". See generally Harnad, S., Brody, T., Vallieres, F., Carr, L., Hitchcock, S., Gingras, Y, Oppenheim, C., Stamerjohanns, H., and Hilf, E., The green and the gold roads to Open Access, Nature Web Focus (2004), http://www.nature.com/nature/focus/accessdebate/21.html. doi:10.1371/journal.pone.0127502.

22 See Shavell S. (2009), Should Copyright of Academic Works be Abolished?. The Journal of Legal Analysis, Forthcoming; Harvard Law and Economics Discussion Paper No. 655; Harvard Public Law Working Paper No. 10-10. Available at SSRN: http://ssrn.com/abstract=1525667. See Guédon J. C., In Oldenburg's long shadow: Librarians, Research Scientists, Publishers, and the Control of Scientific Publishing, ARL Proceedings, 2001. 